\title{
A murine model for cerebral toxocariasis: characterization of host susceptibility and behaviour
}

\author{
C. M. HAMILTON ${ }^{1}$, P. STAFFORD ${ }^{1}$, E. PINELLI ${ }^{2}$ and C. V. HOLLAND ${ }^{1 *}$ \\ ${ }^{1}$ Parasitology Research Group, School of Natural Sciences, Department of Zoology, University of Dublin, Trinity College, \\ Dublin 2, Ireland \\ ${ }^{2}$ Department of Parasitology and Mycology, Diagnostic Laboratory for Infectious Diseases and Perinatal Screening, \\ National Institute for Public Health and Environment (RIVM), Bilthoven, The Netherlands
}

(Received 18 Fuly 2005; revised 4 September and 14 December 2005; accepted 19 December 2005; first published online 14 February 2006)

\author{
SUMMARY
}

Toxocara canis, the parasitic roundworm of dogs, can infect a number of paratenic hosts, such as mice and humans, due to the widespread dissemination of its ova in the environment. In these paratenic hosts, larvae have been shown to exhibit a predilection for the central nervous system, resulting in an increasing number of parasites migrating to the brain as infection progresses. In an initial experiment, we investigated the differential brain involvement of T. canis in 7 strains of inbred mice, and chose 2 strains, susceptible (BALB/c) and resistant $(\mathrm{NIH})$ to cerebral infection. In a second experiment, both strains were investigated in terms of course of migration, larval accumulation, and behavioural response to $T$. canis infection. Results revealed that infected $\mathrm{BALB} / \mathrm{c}$ mice took significantly longer to drink from a water source (following a period of deprivation), compared with control mice, indicating some degree of memory impairment. Cerebral larval recoveries from both strains of mice demonstrated variation between the two experiments, suggesting that larval burdens may not be a reliable indicator of susceptibility or resistance to $T$. canis infection. The percentage of total recovered larvae in each organ may be a better representation of larval distribution. Our model system may provide insights into the impact of chronic geohelminth infection on cognitive development.

Key words: Toxocara canis, inbred mice, brain, visceral larva migrans, behaviour, learning and memory, activity.

\section{INTRODUCTION}

Toxocara canis, the parasitic roundworm of dogs, can infect a number of abnormal (or paratenic) hosts such as mice and humans, due to the widespread dissemination of its ova in the environment. Following ingestion of infective eggs, second-stage larvae hatch in the intestine, and undergo a somatic migration through various organs of the body, though they do not develop to adulthood in the intestine. Toxocariasis may manifest as several clinical syndromes, involving visceral organ invasion and ocular disease (Taylor et al. 1987; Wilder, 1950; Beaver et al. 1952). A phenomenon of ecological significance in mice, and of potential public health significance in man, is that larvae exhibit a predilection for the central nervous system, resulting in an increasing number of parasites migrating to the brain as infection progresses (Sprent, 1955; Lee, 1960; Dunsmore, Thompson and Bates, 1983; Skerret and Holland, 1997). Smith (1991) reported that the migration pathway of larvae in humans and mice is very similar,

* Corresponding author: Parasitology Research Group, School of Natural Sciences, Department of Zoology, University of Dublin, Trinity College, Dublin 2, Ireland. Tel: +353(0)1 6081063. Fax: + $353(0) 16778094$.

E-mail: cholland@tcd.ie and that lesions elicited in experimental mouse models and humans are also comparable. Due to these parallels, the mouse model has been widely used to study toxocariasis. Furthermore, rodents caught in the wild have been shown to harbour Toxocara larvae in their tissues and so have been hypothesized to contribute to parasite transmission if consumed by an appropriate definitive host (Dubinsky et al. 1995).

The mouse model has been used to study the impact of Toxocara infection on different aspects of murine behaviour, including baseline activity, social behaviour, and learning and memory. In general, infected mice appear less active and explorative, less responsive to novelty, and less aversive to open areas and predator stimuli than uninfected animals (Burright et al. 1982; Dolinsky, Burright and Donovick, 1981; Cox and Holland, 1998, $2001 a, b)$. The extent of some behavioural changes could be correlated with larval burdens in the brain (Cox and Holland, 1998, $2001 a, b)$ - such changes being more likely due to non-specific side-effects of induced pathology rather than any adaptive manipulation of host behaviour (Holland and Cox, 2001). In previous studies, larval burdens have been shown to vary between individual outbred mice receiving the same inocula (Cox and Holland, $2001 a$; Skerrett and Holland, 1997), suggesting a possible role of 
immunity and host genetics in the establishment of cerebral infection.

A large proportion of the above studies assessed murine behavioural alterations using outbred mice as models, with inbred strains receiving less attention. Individual inbred mouse strains, produced by brother-sister mating for at least 20 generations, result in animals genetically identical at $>99 \%$ of loci. Utilized for immunological and genetic studies, due to the isogenicity within strains and the genetic heterogeneity between strains, they have transpired to be extremely useful tools for studying the interplay between genes and environment (Festing and Fisher, 2000; Beck et al. 2000). Undertaking behavioural studies with inbred mice is attractive since any infection-induced behavioural alterations that could be potentially masked in heterogeneous outbred mice, may appear more pronounced. We acknowledge that this may reduce applicability to wild populations but does increase experimental control. Since there can be great heterogeneity between inbred strains, their use also allows for the comparison and analysis of behavioural alterations in completely divergent strains.

We investigated the differential brain involvement of $T$. canis in 7 different strains of inbred mice in order to choose a strain susceptible and resistant to larval establishment in the brain. We then investigated the 2 divergent strains in terms of larval accumulation, and behavioural and immune response. This model system will provide a novel opportunity to investigate the genetic factors contributing to brain involvement, and the interaction between host behaviour and infection.

\section{MATERIALS AND METHODS}

\section{Mouse maintenance}

Male inbred mice were purchased from Harlan UK Limited, at 6-8 weeks old. A total of 140 inbred mice were purchased for Experiment 1 (20 each of the strains $\mathrm{A} / \mathrm{J}, \mathrm{BALB} / \mathrm{c}, \mathrm{CBA} / \mathrm{Ca}, \mathrm{C} 3 \mathrm{H} / \mathrm{HeN}, \mathrm{C} 57 \mathrm{BL} /$ $6 \mathrm{~J}, \mathrm{SWR}$ and $\mathrm{NIH}$ - chosen to represent a range of haplotypes), and a further 190 mice for Experiment 2 (95 each of BALB/c and $\mathrm{NIH}$ ). Mice were housed in an animal maintenance room for the duration of the experiments, in standard plastic cages with sawdust bedding. The room was maintained at approximately $22{ }^{\circ} \mathrm{C}$, and operated on a $12 \mathrm{~h}$ light/dark photoperiod. Water and pelleted commercial food were supplied ad libitum, and cages were cleaned on a regular basis. The mice were individually weighed on arrival, and randomly assigned, within each strain, to groups of 5 per cage.

\section{Infection of mice}

Mice were allowed to acclimatize for 1 week prior to commencing experiments. In Exp. 1, 140 mice were each orally inoculated by stomach intubation with $2000 T$. canis ova suspended in $0 \cdot 2 \mathrm{ml}$ of distilled water. In Exp. 2, 120 mice were intubated with $T$. canis ova and 70 control mice intubated with distilled water. The inocula were supplied by the National Institute for Public Health and Environment (RIVM), The Netherlands. A dose of 2000 ova was chosen as it has previously been shown to be sufficient to cause differences in behaviour, without causing debilitation (Cox and Holland, 1998). All mice were monitored hourly after infection for $12 \mathrm{~h}$, for signs of post-inocula trauma or ill effects, although none were shown. In Exp. 2 infection was allowed to establish over a 35-day period before behavioural testing commenced. Previous research has shown that $T$. canis larvae stabilize in the brain of infected mice between days 35 and 42 post-infection (Burren, 1971), and Good (1998) demonstrated that they peaked by day 35 post-infection in outbred CD1-ICR mice.

\section{Larval counts}

(i) Experiment 1. Five mice per strain were sacrificed by cervical dislocation on days 7, 14, 35 and 42 p.i. Larvae were recovered from brain, lungs, liver and right hind-leg muscle using the Baermann technique (Pritchard and Kruse, 1982), modified to reduce evaporation. Larvae were enumerated in the brains of all strains of mice in order to identify a susceptible and resistant strain. Once these strains had been chosen (BALB/c and NIH), larvae were enumerated in their liver, lungs and musculature. Enumeration was carried out following the same examination procedure as that described by Cox and Holland (1998).

(ii) Experiment 2. Five mice per strain were sacrificed on days 3, 7, 14, 35 and 97 p.i., and 20 mice per strain were killed on day 42 p.i., following behavioural experiments (10 infected and 10 control - two groups of 5 mice in each case). Larvae were recovered from the brain, liver, lungs and musculature, and enumerated as before. Exp. 2 was originally proposed to incorporate day 120 p.i., however, by day 97 p.i. some of the mice were exhibiting central nervous symptoms (i.e. loss of co-ordination and balance), so for ethical reasons, the mice were sacrificed on this day.

\section{Behavioural testing - Exp. 2}

(i) Activity. Activity was determined prior to infection, and again on day 35 p.i. The behaviour of individual mice was measured by observing their activity in the homecage. Six different categories of murine behaviour were measured, based on previous research (Hutchison et al. 1980). (1) Ambulation walking, running, jumping, rolling, circling, stretching. (2) Grooming - biting coat, licking coat, washing 
face, scratching, washing genitals, chewing tail. (3) Rearing - standing on cage, straight rearing. (4) Digging - digging bedding backwards, pushing bedding forwards. (5) Immobility - lying on stomach, standing still. (6) Climbing - on bars (upside down).

Testing was performed in silence, with food and water removed, on 2 consecutive days (testing 1 strain per day) between $09.00 \mathrm{~h}$ and $19.00 \mathrm{~h}$. Before testing each mouse, the other 4 mice were removed from the homecage, and the cage was placed in the testing location - i.e. in such a position that the mouse could not see the observer. A 5-min habituation period preceded testing to allow the mouse to acclimatize to being alone in the homecage. The behaviour of the mouse was then recorded over a 20-min period on videotape using a Sony Camcorder, suspended above the cage, and linked to a video-monitor, allowing the animal's behaviour to be observed from a discrete position. Analysis of the videos was performed blind, using a True Basic ${ }^{\odot}$ computer programme (Cox, 1996), which produced an individual summary of behaviour for each mouse over the 20 -min period.

(ii) Learning and memory. The water-finding apparatus used in this test was similar to that described by Cox and Holland (2001 b), consisting of an openfield enclosure with a Perspex-covered alcove situated on the back wall. The floor of the open field was divided into 15 identical squares to allow measurement of the subject's movement. A water-bottle was suspended from the centre of the alcove ceiling, with its tip $6 \mathrm{~cm}$ above the floor. Habituation involved placing each mouse in the left-hand corner of the apparatus and monitoring its behaviour over a 3-min period, making the following measurements: the number of squares crossed in the open field, the number of times the subject touched or sniffed the water-bottle in the alcove, and the number of rears performed. After the habituation period, mice were returned to their homecage, and tested $48 \mathrm{~h}$ later, having been deprived of water $24 \mathrm{~h}$ pre-test. Testing followed the same pattern as habituation, and the following measurements were taken: the time taken to enter the alcove after beginning exploration, the time taken to touch or sniff the water-bottle after beginning exploration, and the time taken to drink from the water-bottle after beginning exploration. In cases where the mouse did not find the water-bottle, or drink, the animal was given the maximum time latency (180 s). All behaviours were recorded on a Sony camcorder as before.

\section{Statistical analysis}

All statistical analysis was carried out at the $95 \%$ confidence limit, and data were checked for normality prior to testing using the Levene test of homogeneity.

(i) Experiment 1. Overall effects of day and strain on larval recoveries from the brain were investigated across all 7 strains of mice by means of a 2-way ANOVA, and F-ratios, with degrees of freedom, and $P$ values are given in the text. Separate strain comparisons were made using least significant difference (LSD) post-hoc tests, in order to ascertain a resistant and susceptible strain of mouse (with regard to cerebral larval establishment), and $P$ values are reported in the text. Once the susceptible and resistant strains had been chosen, effects of day and strain on larval recoveries from the brain and visceral organs were investigated using a MANOVA, which allowed for more than one observed variable to be analysed at once - since the number of larvae in the organs may not be independent of each other. Between-factor differences by both day and strain were investigated using LSD post-hoc tests, and the appropriate statistics are quoted where necessary.

Effects of day and strain on the percentages of total larvae recovered from each organ were investigated using a MANOVA with post-hoc tests (data were arcsine square root transformed prior to analysis), and $\mathrm{F}$ ratios, with degrees of freedom, and $P$ values are given where appropriate. Separate 2-way ANOVAs with post-hoc tests were then performed for each strain to further investigate the effects of organ and day on larval recoveries, and for each day post-infection to investigate the effects of strain and organ on larval recoveries. Appropriate statistics are reported in the text.

(ii) Experiment 2. A MANOVA with post-hoc tests was used to investigate effects of day and strain on larval recoveries from the brain and visceral organs of BALB/c and NIH mice, and F ratios, with degrees of freedom, and $P$ values are given in the text. As for Exp.1, effects of day and strain on the percentages of total larvae recovered from each organ were investigated using a MANOVA (on transformed data), and statistics are given in text. Separate 2-way ANOVAs with post-hoc tests were then performed for each strain to further investigate the effects of organ and day on larval recoveries, and appropriate statistics are reported.

Effects of strain and infection status on each of the observed behavioural activities were assessed using a MANOVA with post-hoc tests. F ratios, with degrees of freedom, and $P$ values are given in the text. Results from the water-finding task were analysed using a 2-way ANOVA, to determine effects of strain, infection status, and the interaction between these factors, on observed activities, and $P$ values from LSD post-hoc tests are reported. Chi-square analysis was used to assess the numbers of mice that drank compared to those that did not, for both strains, and the appropriate statistics are given.

In order to assess any effect of cage on behavioural observations, nested 2-way ANOVAs were carried out for each set of behavioural data, where cage was a random factor nested within the interaction between 
Table 1. Mean Toxocara canis larval burdens (with standard deviations) recovered from the brains of 7 inbred strains of mice on days $7,14,35$ and 42 post-infection

\begin{tabular}{lllll}
\hline \hline \multirow{5}{*}{ Strain } & \multicolumn{4}{l}{ Days post-infection } \\
\cline { 2 - 5 } & 7 & 14 & 35 & 42 \\
\hline $\mathrm{A} / \mathrm{J}$ & $211(31 \cdot 5)$ & $215(39 \cdot 4)$ & $222(68 \cdot 4)$ & $294(24 \cdot 8)$ \\
$\mathrm{BALB} / \mathrm{c}$ & $205(76 \cdot 9)$ & $340(143 \cdot 7)$ & $371(148 \cdot 4)$ & $356(117 \cdot 7)$ \\
$\mathrm{CBA} / \mathrm{Ca}$ & $189(55 \cdot 8)$ & $366(102 \cdot 1)$ & $380(81 \cdot 6)$ & $361(122 \cdot 0)$ \\
$\mathrm{C} 3 \mathrm{H} / \mathrm{HeN}$ & $195(80 \cdot 2)$ & $246(65 \cdot 7)$ & $361(32 \cdot 3)$ & $305(121 \cdot 9)$ \\
$\mathrm{C} 57 \mathrm{BL} / 6 \mathrm{j}$ & $142(62 \cdot 9)$ & $372 \cdot 5(137 \cdot 5)$ & $326(36 \cdot 1)$ & $382 \cdot 5(123 \cdot 3)$ \\
NIH & $93(40 \cdot 4)$ & $242(90 \cdot 4)$ & $238(145 \cdot 3)$ & $124(89 \cdot 3)$ \\
SWR & $163 \cdot 7(33 \cdot 5)$ & $188 \cdot 7(92 \cdot 8)$ & $287(66 \cdot 4)$ & $272 \cdot 5(105 \cdot 4)$ \\
\hline \hline
\end{tabular}

strain and infection status. In the case of activity, where multiple comparisons were carried out on essentially the same data set (since each activity is not independent of the others), the Bonferroni method was applied, reducing the critical $P$ value from $0 \cdot 05$ to $0 \cdot 008$.

\section{RESULTS}

\section{Larval counts}

(i) Experiment 1. Toxocara canis larvae were recovered from the brains of all strains of mice, on each post-mortem date in Exp. 1, and recoveries, as a percentage of inoculum, ranged from 3 to $19 \%$ (Table 1). In all strains, larvae had reached the brain in appreciable numbers by as early as day 7 p.i. - the highest numbers being observed in the brains of $\mathrm{A} / \mathrm{J}$ mice. The general pattern of accumulation in the brain mirrored that of previous studies, i.e. numbers increased over the course of infection, and peaked around day 35 p.i. The number of larvae recovered from NIH mice was generally lower than all other strains, with the highest burden being recovered on day 35 p.i.

A 2-way ANOVA revealed overall significant effects of day and strain on the numbers of larvae in the brain (day: $F_{3,107}=17 \cdot 0, P \leqslant 0 \cdot 0001$; strain: $\left.F_{6,107}=7 \cdot 3, P \leqslant 0 \cdot 0001\right)$. Post-hoc tests demonstrated that larval recoveries from BALB/c mice differed significantly from NIH mice on days 7,35 and 42 p.i. $(P=0 \cdot 05,0 \cdot 02$, and $\leqslant 0 \cdot 0001$, respectively) (Fig. 1), and larval recoveries from $\mathrm{CBA} / \mathrm{Ca}$ mice also differed significantly from NIH mice on days 14,35 and 42 $(P=0 \cdot 03,0 \cdot 01$, and $\leqslant 0 \cdot 0001$, respectively $)$. Since NIH mice carried the lowest larval burden overall, these mice were chosen as the resistant strain to $T$. canis infection. BALB/c mice were chosen over $\mathrm{CBA} / \mathrm{Ca}$ mice as the susceptible strain, since these mice had a statistically higher larval burden in the brain than NIH mice on days 7, 35 and 42 p.i., and they had previously been reported to be more susceptible to toxocariasis.

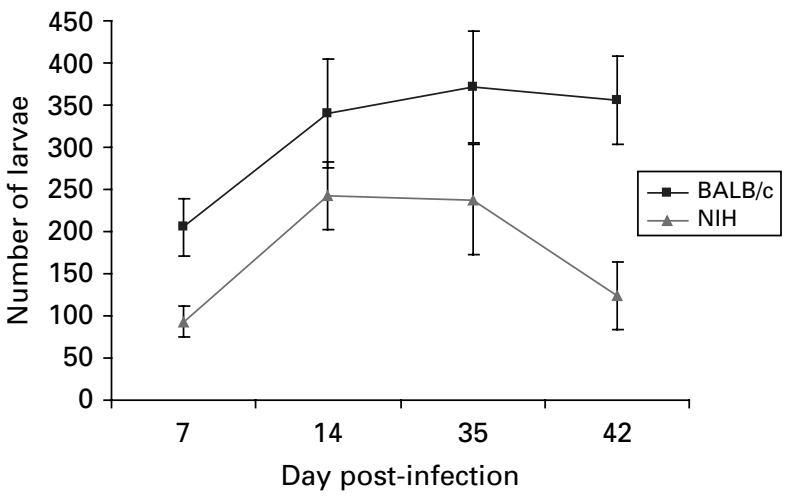

Fig. 1. Mean number ( \pm s.E.M.) of larvae recovered from the brains of Toxocara canis-infected BALB/c and NIH mice in Exp. 1.

Results from a MANOVA demonstrated significant effects of day and strain on larval recovery from all organs of BALB/c and NIH mice (day: $F_{3,93}=2 \cdot 6$, $P=0.004$; strain: $\left.F_{1,29}=4.5, P=0.006\right)$. Highest larval recovery from the lungs of both strains of mice occurred on day 7 p.i. (mean \pm s.D. : $44 \pm 17 \cdot 10$ and $24 \pm 11 \cdot 40, \mathrm{BALB} / \mathrm{c}$ and $\mathrm{NIH}$ mice respectively) and then decreased as infection progressed, although overall numbers were higher in BALB/c mice. LSD post-hoc tests demonstrated a significantly higher lung burden in BALB/c mice on day 7 p.i. compared with NIH mice $(P=0 \cdot 005)$. Recoveries on all other days were similar between strains. The number of larvae recovered from the liver increased over infection, with both strains carrying similar burdens on days 7, 35 and 42 p.i. The number of larvae recovered from the musculature was generally lower than the other organs, and varied throughout infection. Posthoc tests demonstrated that BALB/c mice had a significantly higher larval burden in their muscle than NIH mice on day 42 p.i. $(P=0 \cdot 006)$.

When total numbers of larvae recovered from each mouse were compared between strains, it was noted that more larvae were recovered from $\mathrm{BALB} / \mathrm{c}$ than $\mathrm{NIH}$ mice. Larval recoveries from each organ were then investigated as a percentage of the total recovery. 
On all days post-infection, the vast majority of larvae were recovered from the brains of BALB/c and NIH mice compared to all other organs. Results of a MANOVA revealed significant effects of day and strain on larval recoveries (day: $F_{3,93}=2 \cdot 99, P=$ $0 \cdot 001$; strain: $\left.F_{1,29}=3 \cdot 25, P=0 \cdot 026\right)$. Separate 2 -way ANOVAs for each strain revealed significant effects of organ and the interaction between organ and day, on the percentage of larvae recovered (BALB/c: organ: $F_{\mathbf{3}, 64}=502 \cdot 25, P \leqslant 0 \cdot 0001$; organ $\times$ day : $F_{\mathbf{9}, \mathbf{6 4}}=$ $5.43, P \leqslant 0.0001$; NIH: organ: $F_{3,64}=145 \cdot 2, P \leqslant$ $0 \cdot 0001$; $\operatorname{organ} \times$ day: $\left.F_{\mathbf{9}, \mathbf{6 4}}=3 \cdot 00, P=0 \cdot 005\right)$. Posthoc tests revealed that there were significantly more larvae recovered from the brain than in the visceral organs, on all days post-infection, for both strains $(P \leqslant 0 \cdot 0001$, for all comparison). Post-hoc tests from separate 2-way ANOVAs for each day post-infection revealed that a significantly lower percentage of larvae were recovered from the brains of NIH mice on days 35 and 42 post-infection, compared with BALB/c (day 35 p.i.: $P=0 \cdot 04$; day 42 p.i. $=0 \cdot 007$ ). There were fewer larvae recovered on days 7 and 14 p.i. also, although the differences did not reach statistical significance.

(ii) Experiment 2. Larvae were recovered from the brains of BALB/c and NIH mice on all days postinfection in Exp. 2. Although the recoveries, as a percentage of inoculum, were similar to Exp. 1 (ranging from 3 to $18 \%$ ), the individual counts for each day p.i. were very different to the first experiment, and, in fact, the strains no longer appeared to be divergent. The counts for both strains were very similar, with larval numbers increasing in both strains between days 3 and 7 p.i., then decreasing slightly by day 14 p.i., before increasing again. On day 42 p.i. there were more larvae in the brains of NIH mice compared with BALB/c mice (mean \pm S.D.: $350 \cdot 8 \pm 35 \cdot 5$ and $277 \pm 64 \cdot 5$, respectively). By day 97 p.i., however, more larvae were in the brains of BALB/c mice, and larval numbers had decreased in the brains of NIH mice (mean \pm s.D.: $304 \cdot 4 \pm$ $113 \cdot 1$ and $250 \cdot 7 \pm 42 \cdot 9$, respectively).

Results of a MANOVA showed a significant effect of day, but not strain, on larval recoveries from all organs of BALB/c and NIH mice (day: $F_{5,168}=$ $4 \cdot 45, P \leqslant 0 \cdot 0001)$. LSD post-hoc tests demonstrated no significant differences in larval burdens in the brains of $\mathrm{BALB} / \mathrm{c}$ and $\mathrm{NIH}$ mice. Larval recoveries from the liver and lungs were very similar between strains on all days post-infection. Highest recoveries from the liver occurred on day 3 p.i. (mean \pm s.D.: BALB/c: $228 \pm 85 \cdot 56$; NIH: $199 \pm 164 \cdot 22)$, and then decreased dramatically by day 7 p.i. (mean \pm s.D.: $\mathrm{BALB} / \mathrm{c}: 35 \pm 14 \cdot 14$; NIH: $47 \cdot 5 \pm 11 \cdot 90)$, and remained low for the duration of infection. A similar pattern was seen in the lungs - with highest recoveries from both strains being made on day 3 p.i., and numbers decreasing by day 7 p.i., and remaining

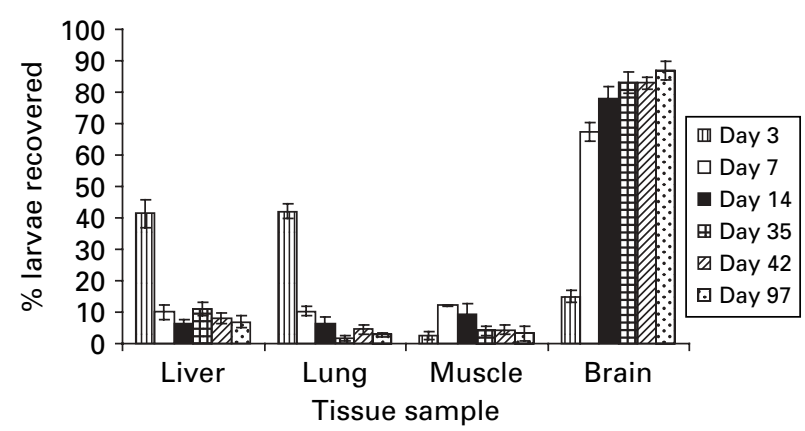

Fig. 2. Mean percentage ( \pm s.E.M.) of total larvae recovered from each organ of Toxocara canis-infected BALB/c mice in Exp. 2.

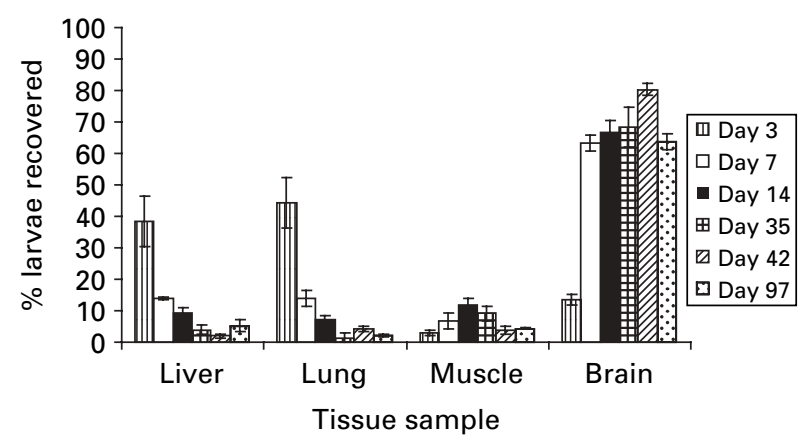

Fig. 3. Mean percentage ( \pm s.E.M. $)$ of total larvae recovered from each organ of Toxocara canis-infected NIH mice in Exp. 2.

low throughout infection. Larval recoveries from the musculature varied throughout infection, and numbers peaked in BALB/c mice on day 7 p.i., and in NIH mice on day 14 p.i. Numbers then decreased over infection. Post-hoc tests revealed that BALB/c mice carried a significantly higher larval burden in the muscle than NIH mice on day 7 p.i. $(P=0.03)$.

On the whole, the total number of larvae recovered from mice over the course of infection was similar in both strains, but generally lower than Exp. 1. As for Exp. 2, larval recoveries from each organ were investigated for each strain as a percentage of total larvae recovered, and are shown in Figs 2 and 3. It is clear to see that in early infection, the majority of larvae were recovered from liver and lungs and, as infection progressed, the percentage of larvae recovered from these organs decreased and the majority of larvae were recovered from the brain. Results of a MANOVA revealed significant effects of day, strain and the interaction between these factors, on the percentage of larvae recovered (day: $F_{5,168}=6 \cdot 17$, $P \leqslant 0 \cdot 0001$; strain: $F_{1,39}=12 \cdot 18, P \leqslant 0 \cdot 0001$; day $\times$ strain: $\left.F_{5,168}=1 \cdot 87, P=0 \cdot 017\right)$. Post-hoc tests demonstrated that $\mathrm{BALB} / \mathrm{c}$ mice carried a significantly higher percentage of larvae in the liver on days 35 and 42 p.i. compared with NIH mice $(P=0 \cdot 02$, for both comparisons). More notably, post-hoc tests demonstrated that NIH mice carried a significantly lower percentage of larvae in the brain on days 14,35 and 


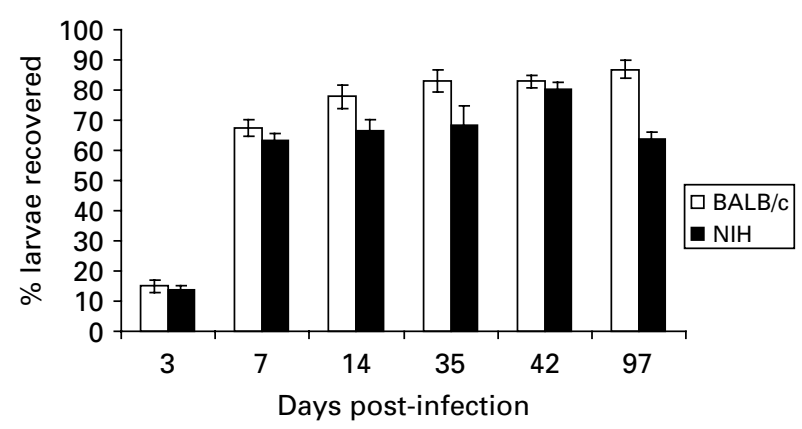

Fig. 4. Mean percentage ( \pm s.E.M.) of total larvae recovered from the brains of Toxocara canis-infected BALB/c and NIH mice in Exp. 2.

97 p.i., compared with BALB/c mice (day 14 p.i.: $P=0.02$; day 35 p.i.: $P=0.003$; day 97 p.i.: $P \leqslant$ 0.0001) (Fig. 4).

Separate 2-way ANOVAs for each strain revealed significant effects of day (in the case of NIH mice only), organ, and the interaction between organ and day, on the percentage of larvae recovered (BALB/c: organ: $F_{3,92}=435 \cdot 13, P \leqslant 0 \cdot 0001$; organ $\times$ day: $F_{15,92}=34 \cdot 14, P \leqslant 0 \cdot 0001 ; \mathrm{NIH}:$ day: $F_{5,76}=$ $4 \cdot 37, P=0 \cdot 0015$; organ: $F_{3,76}=226 \cdot 35, P \leqslant 0 \cdot 0001$; organ $\times$ day: $\left.F_{15,76}=24 \cdot 98, \quad P \leqslant 0 \cdot 0001\right)$. Post-hoc tests revealed that a significantly higher percentage of larvae were recovered from the liver and lungs of both strains on day 3 p.i., compared with the muscle and brain ( $P \leqslant 0 \cdot 0001$, for all comparisons). The tests also revealed that from day 7 p.i. onwards, a significantly higher percentage of larvae were recovered from the brains of both strains of mice compared with the other organs $(P \leqslant 0 \cdot 0001$, for all comparisons).

\section{Behavioural testing}

(i) Activity. The activity of BALB/c and NIH mice differed prior to infection (data not shown). BALB/c mice spent most of their time climbing, digging, and rearing, followed by ambulating and grooming. They spent very little time immobile. NIH mice spent most of their time rearing, and rest of the time was split similarly between ambulating, climbing and digging. Like BALB/c mice, NIH mice spent very little time immobile. Post-infection, BALB/c mice spent similar amounts of time ambulating, digging and rearing, much less time climbing and grooming, and were more immobile than pre-infection. NIH mice spent similar amounts of time ambulating, rearing, grooming and climbing, although in the latter activity, this was much reduced in infected mice. They spent much less time digging, and were more immobile, although this was more pronounced in the infected mice. Due to these differences between and within strains, statistical analysis for activity was performed on post- minus pre-infection data, and differences in activity are shown in Figs 5 and 6.

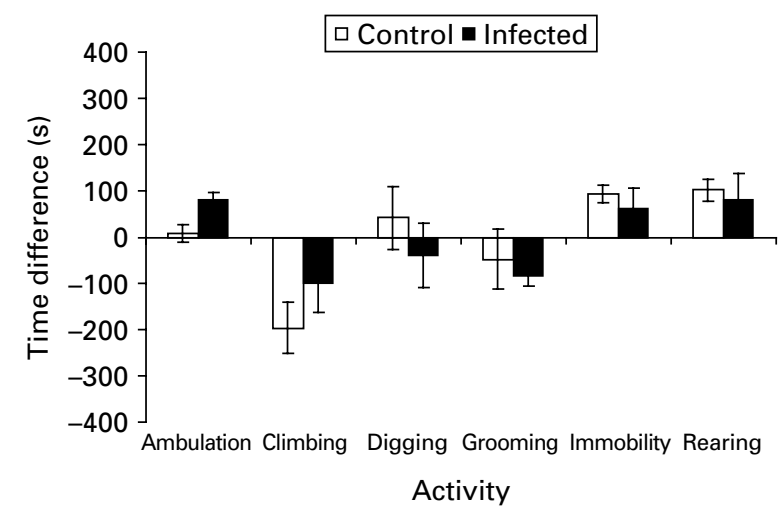

Fig. 5. Mean time difference ( \pm s.E.M.) spent at each activity between pre- and post-infection, in BALB/c mice.

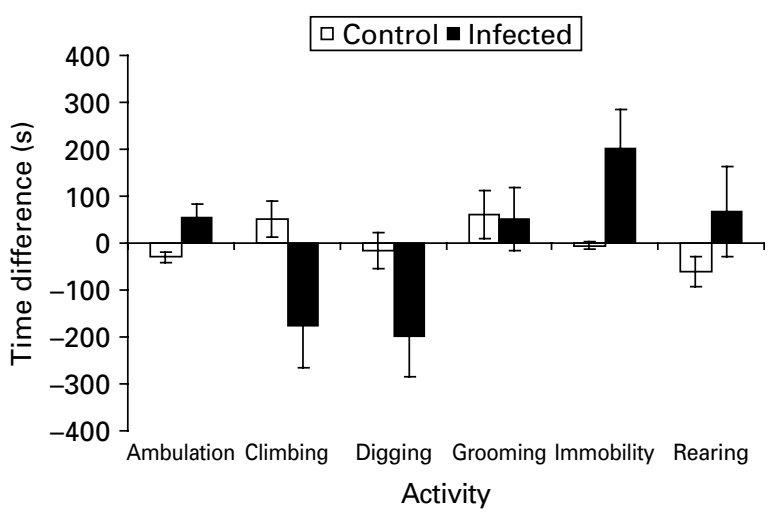

Fig. 6. Mean time difference ( \pm s.E.M.) spent at each activity between pre- and post-infection, in NIH mice.

Fig. 5 demonstrates that, overall, BALB/c mice spent more time ambulating, rearing and had longer periods of immobility after infection, and less time climbing and grooming compared with pre-infection. The time spent digging differs between control and infected mice - with infected mice spending less time at this activity. Fig. 6 demonstrates that, overall, NIH mice spent slightly more time grooming, less time digging, and much more time immobile, after infection - although the latter activity differs between control and infected mice. Time spent ambulating, climbing and rearing differs between control and infected mice, with infected mice spending less time climbing and more time rearing and ambulating. Results of a MANOVA demonstrated overall effects of strain, infection status and the interaction between these two factors on activity levels (strain: $F_{1,30}=2 \cdot 75, P=0 \cdot 037$; infection status : $F_{1,30}=10 \cdot 61$, $P \leqslant 0 \cdot 0001$; strain $\times$ infection status: $F_{1,30}=4 \cdot 88$, $P=0 \cdot 002)$. Post-hoc tests revealed that both infected $\mathrm{BALB} / \mathrm{c}$ and NIH mice spent significantly more time ambulating compared with control mice (BALB/c: $P=0 \cdot 005$; NIH: $P=0 \cdot 003)$. However, infected NIH mice were also significantly more immobile than their control counterparts $(P=0 \cdot 002)$, and spent significantly less time climbing $(P=0 \cdot 018)$, whereas 
Table 2. Behavioural observations ( \pm s.D.) recorded for control and Toxocara canis-infected BALB/c and NIH mice, during the habituation period of the water-finding task

\begin{tabular}{|c|c|c|c|c|}
\hline \multirow{2}{*}{ Behaviour } & \multicolumn{2}{|l|}{$\mathrm{BALB} / \mathrm{c}$} & \multicolumn{2}{|l|}{$\mathrm{NIH}$} \\
\hline & Control & Infected & Control & Infected \\
\hline No. of squares crossed & $52 \cdot 1 \pm 23 \cdot 9$ & $45 \cdot 9 \pm 43 \cdot 7$ & $65 \cdot 6 \pm 30 \cdot 3$ & $32 \cdot 5 \pm 25 \cdot 6$ \\
\hline $\begin{array}{l}\text { No. of times mouse } \\
\text { touched water bottle }\end{array}$ & $9 \cdot 7 \pm 0 \cdot 6$ & $6 \cdot 9 \pm 4 \cdot 4$ & $5 \cdot 4 \pm 3 \cdot 3$ & $3 \cdot 0 \pm 1 \cdot 9$ \\
\hline No. of rears performed & $11 \cdot 1 \pm 7 \cdot 6$ & $2 \cdot 5 \pm 2 \cdot 0$ & $20 \cdot 0 \pm 12 \cdot 2$ & $3 \cdot 4 \pm 4 \cdot 2$ \\
\hline
\end{tabular}

there were no significant differences between control and infected BALB/c mice for these activities. Infected NIH mice spent less time digging and grooming, and more time rearing compared with control mice, but the differences were not significant. Infected BALB/c mice also spent less time digging and grooming than control mice, but the differences were not significant.

Results of separate nested 2-way ANOVAs carried out for each activity, with cage as a random factor nested within the interaction between strain and infection status, revealed a significant effect of cage on the level of rearing observed $(P=0 \cdot 002)$.

(ii) Learning and memory. During habituation (Table 2), significant differences were noted between, and within, both strains of mice for some of the measurements recorded. Post-hoc tests, from separate 2-way ANOVAs for each observation, revealed that infected NIH mice crossed significantly fewer squares in the open field $(P=0.037)$, and performed significantly fewer rears $(P \leqslant 0 \cdot 0001)$, compared with control mice. They also touched/sniffed the water-bottle significantly less often than infected $\mathrm{BALB} / \mathrm{c}$ mice $(P=0 \cdot 012)$. Infected $\mathrm{BALB} / \mathrm{c}$ mice also performed significantly fewer rears than their control counterparts $(P=0.018)$, and touched/ sniffed the water-bottle fewer times than the control mice, although this difference did not reach significance $(P=0 \cdot 06)$. Results of separate nested 2-way ANOVAs for each activity revealed a significant effect of cage on the number of times the water-bottle was touched/sniffed $(P=0 \cdot 04)$.

During the testing period, 9 out of 10 control $\mathrm{BALB} / \mathrm{c}$ mice drank from the water-bottle, compared with only 2 out of 10 infected BALB/c mice $\left(\chi^{2}=9 \cdot 899, P=0 \cdot 002\right.$, D.F. $\left.=1\right)$, and 6 out of 10 control NIH mice drank, compared with 3 out of 8 infected NIH mice $\left(\chi^{2}=0 \cdot 900, P=0 \cdot 343\right.$, D.F. $\left.=1\right)$. Post-hoc tests, from 2-way ANOVAs for each activity, revealed that infected $\mathrm{BALB} / \mathrm{c}$ mice took longer to enter the alcove, and find the water-bottle, after beginning exploration, compared with control mice, although these differences were not significant (Fig. 7 ; time taken to enter alcove: $P=0 \cdot 121$; time taken to find water-bottle: $P=0 \cdot 06)$. There were

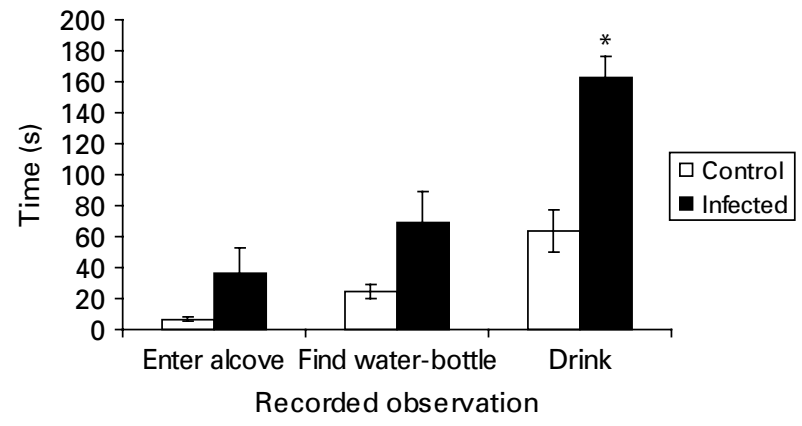

Fig. 7. Mean time ( \pm s.E.M.) taken by control and infected $\mathrm{BALB} / \mathrm{c}$ mice to carry out the various observations recorded during the water-finding, tasktesting period (* comparison of infected and control mice, $P \leqslant 0 \cdot 0001)$.

significant effects of infection status, and the interaction between strain and infection, on the time it took for mice to start drinking after beginning exploration (infection status: $F_{1,34}=16 \cdot 73, P=0 \cdot 0002$; strain $\times$ infection status: $\left.F_{1,34}=6 \cdot 17, P=0 \cdot 018\right)$. Posthoc tests revealed that infected $\mathrm{BALB} / \mathrm{c}$ mice took a significantly longer amount of time to drink from the water-bottle, compared with control mice $(P \leqslant$ $0 \cdot 0001)$, suggesting some degree of memory impairment (Fig. 7). Although there were no significant differences between control and infected NIH mice, infected mice generally took longer to locate the water-bottle and drink from it compared with control mice.

Results of separate nested 2-way ANOVAs for each activity revealed no significant effect of cage on behavioural observations ( $P>0 \cdot 05$, for all activities).

\section{DISCUSSION}

The most striking result from this study was that Toxocara canis infection led to some degree of memory impairment in infected inbred mice. Spatial awareness, and the ability to use visual cues from the surrounding environment to remember locations of specific resources, is vital to the survival of small rodents. In this study, learning and memory was assessed in $T$. canis-infected mice using a waterfinding task. In general, infected animals showed a 
reduction in exploratory behaviour and spatial awareness, taking longer to enter the alcove (after a period of water-deprivation), and locate and drink from the water-bottle, compared with control animals. These findings were most pronounced in infected BALB/c mice, with animals taking significantly longer to drink from the water-bottle, after beginning exploration, compared with control mice. Infected BALB/ $\mathrm{c}$ mice also took longer to enter the alcove and locate the water-bottle in comparison to control mice, but these differences did not reach statistical significance. Although the time taken to enter the alcove did not differ between infected and control NIH mice, infected NIH mice did take a longer amount of time to locate the water-bottle and drink from it, compared with controls, although these differences did not reach statistical significance. A possible explanation for this may be that the drive to enter the alcove was not influenced by the water source specifically but rather the need for mice to seek narrow places of shelter/safety.

An alternative explanation for infected BALB/c mice taking longer to enter the alcove, and drink from the water bottle, is general lethargy - since parasitic infection can render a subject less energetic than uninfected individuals. Infected $\mathrm{BALB} / \mathrm{c}$ mice could have been more sluggish than uninfected mice and therefore took longer to complete any of the tasks set in the experiment. However, considering the reported activity of these mice, it is evident that although infected BALB/c mice were less active for some recorded behaviours, they were more ambulatory than their control counterparts, and spent less time immobile - suggesting that they were not lethargic. It was also noted that once each subject was returned to the homecage after testing, they displayed an eagerness to drink - indicating that the length of time taken to locate the water source was unlikely due to thirst suppression. In a related experiment, learning and memory was assessed in control and infected BALB/c and NIH mice under the same experimental conditions, although using modified apparatus (Flanagan, 2005). Instead of the open-field apparatus having only one alcove containing the water-bottle, the modified apparatus utilized a further 2 separate alcoves - making it possible to test whether or not the infected subject could correctly relocate the water source after a period of habituation. The results of the related study were similar to the results obtained in the present study, and the most notable finding was that infected BALB/c mice took significantly longer to drink from the water-bottle than uninfected control mice. They also took longer to enter the correct alcove, and locate the water-bottle within, compared with controls, although these differences were not significant. The idea that $T$. canis-infected mice have significantly reduced spatial awareness and exploratory skills during infection carries implications for their survival in the wild, and also implications for cognitive development in children.

Previous studies have reported the possibility of learning and memory retardation due to T. canis infection in outbred mice, but the levels of impairment have rarely reached statistically significant levels (Dolinksy, Burright and Donovick, 1981). In a study using similar apparatus to that used in this study, Cox and Holland (2001 $b$ ) demonstrated that outbred LACA mice in moderate and high larval dose groups showed a greater latency to enter the alcove, locate the water-bottle and drink from it, compared with control mice, suggesting some degree of memory impairment, although the differences were not statistically significant. Olson and Rose (1966) reported that the ability of rats to solve maze problems was impaired as a result of $T$. canis infection, and this effect was dose dependent, with rats infected with 20000 ova making significantly more errors than control rats. Effects on spatial learning have also been reported in infections with other parasites (Kershaw, Leytham and Dickerson, 1959; Kavaliers and Colwell, 1995 ; Kavaliers, Colwell and Galea, 1995), with infected subjects displaying a retardation of ability to learn in comparison with controls. Witting (1979) assessed learning and memory in T. gondiiinfected mice using a series of maze experiments, and reported severe memory impairment in infected animals compared to controls. The level of impairment was also significantly correlated with the number of tissue cysts present in the brain.

Of those studies cited above using mice, behavioural testing was carried out using outbred strains, which could potentially explain the absence of statistical significance in the results. In the present study, we used inbred mice, genetically identical within strains, which could explain why $T$. canisinduced behavioural alterations were more pronounced. The evidence of memory impairment in $T$. canis-infected mice in this study is of particular interest since it was evident in $\mathrm{BALB} / \mathrm{c}$ mice - the chosen susceptible strain-suggesting that heavier cerebral larval burdens lead to significantly more pronounced behavioural alterations.

Exp. 1 identified BALB/c and NIH mice as susceptible and resistant strains (respectively) to cerebral $T$. canis infection, with BALB/c mice carrying a significantly higher larval burden in the brain, compared with NIH mice, on days 7, 35 and 42 p.i. The choice of strains was supported by previous studies where BALB/c mice have been reported to be more susceptible to $T$. canis infection (Bardon, Cuellar and Guillen, 1994 ; Epe et al. 1994), and NIH mice have been reported to show a relatively higher level of resistance to $T$. canis infection than outbred CD1 mice (Abo-Shehada and Herbert, 1989), and have been reported to clear infections with Trichuris muris and Trichinella spiralis more rapidly than other inbred strains (Lee and Wakelin, 1982; Alizadeh and 
Wakelin, 1983 ; Dehlawi and Goyal, 2003). In Exp. 2, larval burdens in the brains of the two chosen strains were similar and they no longer appeared divergent. However, when larval recoveries were expressed as percentages of total burdens, it was evident that a significantly higher percentage of total larvae were recovered from the brains of BALB/c mice compared with NIH mice, on days 14, 35 and 97 post-infection, indicating that these mice are still more susceptible to cerebral infection. These results suggest that actual larval burdens may not be a reliable indicator of susceptibility and resistance to cerebral toxocariasis, and that perhaps a more suitable end-point characteristic would be percentage of total larvae, since it takes into account any variation in the numbers of eggs that hatched successfully after inoculation.

The behavioural changes observed in this study may be due to a number of factors related to larval burden. It is possible that the position of larvae in the brain may influence the types of behaviours altered. Previous studies have reported the presence of larvae in the telencephalon (Good, Holland and Stafford, 2001) and cerebellum (Burren, 1971) of infected mice, which is noteworthy considering these areas of the brain are associated with learning and memory, and co-ordination and control of voluntary movement (respectively). The presence of larvae in the cerebellum is also of relevance to the mice in this study, as by day 97 p.i., infected BALB/c mice were exhibiting central nervous symptoms -i.e. lack of co-ordination and balance.

The quality and quantity of immune response elicited by the infected host may be another factor influencing the magnitude of behavioural changes. Although the systemic immune response to $T$. canis infection has been widely studied (Del Prete et al. 1991; Wang et al. 1995; Kuroda et al. 2001), the immune response in the brain has received no attention. Studies on other parasitic infections of the CNS have demonstrated that, often, cytokines produced in response to infection are responsible for the induction of pathology and neurodegeneration (Restrepo et al. 1998; Brown et al. 1999; Gazzinelli et al. 1993). It could be, therefore, that infected $\mathrm{BALB} / \mathrm{c}$ mice in this study are displaying the consequences of an immune response produced against the parasite. Immunological data obtained from the present study highlight differences in the humoral and cellular responses between the strains, and suggest a link with behavioural changes, but this will be reported elsewhere.

In conclusion, this study has demonstrated that cerebral infection with $T$. canis leads to some level of memory impairment in infected murine hosts. These results are interesting, not only because of the implications they may carry for the animal's survival in the wild, but also because of the wider implications with respect to human infection. Evidence for cerebral toxocariasis in humans is patchy but there are some indications that larval involvement in the human brain may have some subtle public health implications (Hill, Denham and Scholtz, 1985; Marmor et al. 1987; Magnaval et al. 1997). The clinical significance of cerebral infection remains unclear, however, since there are usually other factors involved when the patient presents - such as epilepsy, dementia, and mental retardation (Kaplan et al. 2004; Magnaval et al. 1997; Glickman et al. 1979). Nevertheless, given the results of this study, and the others cited, it is evident that cerebral T. canis infection can lead to behavioural alterations, and although these results are in rodents, they still carry implications for human health, especially given the high seroprevalence of $T$. canis in some countries (Worley et al. 1984; Thomson et al. 1986; Holland et al. 1995), and the close partnership between dog and man. Furthermore, this model system may also provide insights into the impact of chronic geohelminth infection on cognitive development, something that has proved to be very difficult to investigate in human subjects (Holland and Hamilton, 2005).

The authors would like to thank Dr M. Brown and Mr S. Wright for comments on earlier drafts of this manuscript. We also thank M. O'Regan for expert statistical advice, and B. Teahan for help with the larval counts. This project was funded by a Basic Research Award from the Irish Research Council for Science, Engineering and Technology (IRCSET).

\section{REFERENCES}

Abo-Shehada, M. N. and Herbert, I. V. (1989).

Variations in innate resistance to experimental Toxocara canis infection in two strains of mice. Veterinary Parasitology 33, 297-307.

Alizadeh, H. and Wakelin, D. (1983). Genetic factors controlling the intestinal mast cell response in mice infected with Trichinella spiralis. Clinical and Experimental Immunology 49, 331-337.

Bardon, R., Cuellar, C. and Guillen, J. L. (1994). Larval distribution of Toxocara canis in BALB/c mice at nine weeks and one year post-inoculation. Fournal of Helminthology 68, 359-360.

Beaver, P. C., Synder, C. H., Carerra, G. M., Dent, J. H. and Lafferty, J. W. (1952). Chronic eosinophilia due to visceral larva migrans. Pediatrics 9, 7.

Beck, J. A., Lloyd, S., Hafezparast, M., LennonPierce, M., Eppig, J. T., Festing, M. F. W. and Fisher, E. M. C. (2000). Genealogies of mouse inbred strains. Nature Genetics 24, 23-25.

Brown, H., Turner, G., Rogerson, S., Tembo, M., Mwenechanya, J., Molyneux, M. and Taylor, T. (1999). Cytokine expression in the brain in human cerebral malaria. Fournal of Infectious Diseases $\mathbf{1 8 0}$, 1742-1746.

Burren, C. H. (1971). The distribution of Toxocara canis larvae in the central nervous system of the mouse. Transactions of the Royal Society of Tropical Medicine and Hygiene 65, 450-453. 
Burright, R. G., Donovick, P. J., Dolinsky, Z., Hurd, Y. and Cypess, R. (1982). Behavioural changes in mice infected with Toxocara canis. Fournal of Toxicology and Environmental Health 10, 621-626.

Cox, D. M. (1996). The effect of Toxocara canis infection on the paratenic host behaviour of two strains of mice. Unpublished Ph.D. thesis, University of Dublin.

Cox, D. and Holland, C. V. (1998). The relationship between numbers of larvae recovered from the brain of Toxocara canis-infected mice, and social behaviour and anxiety in the host. Parasitology 116, 579-594.

Cox, D. and Holland, C. V. (2001 $a$ ). Influence of mouse strain, infective dose and larval burden in the brain on activity in Toxocara-infected mice. Fournal of Helminthology 75, 23-32.

Cox, D. and Holland, C. V. (2001 b). Relationship between three intensity levels of Toxocara canis larvae in the brain, and effects on exploration, anxiety, learning and memory in the murine host. Fournal of Helminthology 75, 33-41.

Dehlawi, M. S. and Goyal, P. K. (2003). Responses of inbred mice strains to infection with intestinal nematodes. Fournal of Helminthology 77, 119-124.

Del Prete, G. F., De Carli, M., Mastromauro, C., Biagiotti, R., Macchia, D., Falagiani, P., Ricci, M. and Romagnani, S. (1991). Purified protein derivative of Mycobacterium tuberculosis and excretory-secretory antigen(s) of Toxocara canis expand in vitro human $\mathrm{T}$ cells with stable and opposite (type $1 \mathrm{~T}$ helper or type $2 \mathrm{~T}$ helper) profile of cytokine production. Fournal of Clinical Investigation 88, 346-350.

Dolinksy, Z. S., Burright, R. G. and Donovick, P. J. (1981). Behavioural effects of lead and Toxocara canis in mice. Science 213, 1142-1144.

Dubinsky, P., Havasiova-Reiterova, K., Petko, B., Hovorka, I. and Tomasovicova, O. (1995). Role of small mammals in the epidemiology of toxocariasis. Parasitology 110, 187-193.

Dunsmore, J. D., Thompson, R. C. A. and Bates, I. A. (1983). The accumulation of Toxocara canis larvae in the brains of mice. International Fournal for Parasitology 13, 517-521.

Epe, C., Sabel, T., Schnieder, T. and Stoye, M. (1994). The behaviour and pathogenicity of Toxocara canis larvae in mice of different strains. Parasitology Research 80, 691-695.

Festing, M. F. W. and Fisher, E. M. C. (2000). Mighty mice. Nature, London 404, 815.

Flanagan, A. (2005). A murine model for cerebral toxocariasis: contribution of host genotype and infection duration on learning and memory. Unpublished Moderatorship Thesis, University of Dublin.

Gazzinelli, R. T., Eltoum, I., Wynn, T. A. and Sher, A. (1993). Acute cerebral toxoplasmosis is induced by in vivo neutralisation of TNF- $\alpha$ and correlates with the down-regulated expression of inducible nitric oxide synthase and other markers of macrophage activation. Fournal of Immunology 151, 3672-3681.

Glickman, L. T., Cypress, R., Crumrine, P. K. and Gitlin, D. A. (1979). Toxocara infection and epilepsy in children. Fournal of Pediatrics 94, 75-78.

Good, B. (1998). Epidemiological and experimental aspects of Toxocara infection in humans and mice. Unpublished Ph.D. thesis, University of Dublin.
Good, B., Holland, C. V. and Stafford, P. (2001). The influence of inoculum size and time post-infection on the number and position of Toxocara canis larvae recovered from the brains of outbred CD1 mice. Fournal of Helminthology 75, 175-181.

Hill, I. R., Denham, D. A. and Scholtz, C. L. (1985). Toxocara canis larvae in the brain of a British child. Transactions of the Royal Society of Tropical Medicine and Hygiene 79, 351-354.

Holland, C. V., O'Lorcain, P., Taylor, M. R. H. and Kelly, A. (1995). Sero-epidemiology of toxocariasis in school children. Parasitology 110, 535-545.

Holland, C. V. and Cox, D. (2001). Toxocara in the mouse: a model for parasite-altered host behaviour. Fournal of Helminthology 75, 125-135.

Holland, C. and Hamilton, C. (2005). The significance of cerebral toxocariasis. In Toxocara: the Enigmatic Parasite (ed. Holland, C. V. and Smith, H. V.), CABI Publishing, Wallingford, Oxon, UK (in the Press).

Hutchison, W. M., Bradley, M., Cheyne, W. M., Wells, B. W. P. and Hay, J. (1980). Behavioural abnormalities in Toxoplasma-infected mice. Annals of Tropical Medicine and Parasitology 74, 337-345.

Kaplan, M., Kalkan, A., Hosoglu, S., Kuk, S., Özden, M., Demirdag, K. and Ozdarendeli, A. (2004). The frequency of Toxocara infection in mental retarded children. Memorias do Instituto Oswaldo Cruz 99, 121-125

Kavaliers, M. and Colwell, D. D. (1995). Reduced spatial learning in mice infected with the nematode, Heligmosomoides polygyrus. Parasitology 110, 591-597.

Kavaliers, M., Colwell, D. D. and Galea, L. A. M. (1995). Parasitic infection impairs spatial learning in mice. Animal Behaviour 50, 223-229.

Kershaw, W. E., Leytham, G. W. H. and Dickerson, G. (1959). The effect of schistosomiasis on animal intelligence. Annals of Tropical Medicine and Parasitology 53, 504-506.

Kuroda, E., Yoshida, Y., En Shan, B. and Yamashita, U. (2001). Suppression of macrophage interleukin-12 and tumour necrosis factor-alpha production in mice infected with Toxocara canis. Parasite Immunology 23, 305-311

Lee, H. F. (1960). Effects of superinfection on the behaviour of Toxocara canis larvae in mice. Fournal of Parasitology 46, 583-588.

Lee, T. D. G. and Wakelin, D. (1982). The use of host strain variation to assess the significance of mucosal mast cells in the spontaneous cure response of mice to the nematode Trichuris muris. International Archives of Allergy and Applied Immunology 67, 302-305

Magnaval, J.-F., Galindo, V., Glickman, L. T. and Clanet, M. (1997). Human Toxocara infection of the central nervous system and neurological disorders: a case-control study. Parasitology 115, 537-543.

Marmor, M., Glickman, L., Shofer, F., Faich, L., Rosenberg, C., Cornblatt, B. and Friedman, S. (1987). Toxocara canis infection of children: Epidemiologic and neuropsychologic findings. American Fournal of Public Health 77, 554-559.

Olson, L. J. and Rose, J. E. (1966). Effect of Toxocara canis infection on the ability of white rats to solve maze problems. Experimental Parasitology 19, 77-84. 
Pritchard, M. H. and Kruse, G. O. W. (1982). The Collection and Preservation of Animal Parasites.

University of Nebraska Press, Lincoln and London.

Restrepo, B. I., Llaguno, P., Sandoval, M. A., Enciso, J. A. and Teale, J. M. (1998). Analysis of immune lesions in neurocysticercosis patients: central nervous system response to helminth appears Th1-like instead of Th2. Fournal of Neuroimmunology 89, 64-72.

Skerrett, H. and Holland, C. V. (1997). Variation in the larval recovery of Toxocara canis from the murine brain: implications for behavioural studies. Fournal of Helminthology 71, 253-255.

Smith, H. V. (1991). Immune evasion and immunopathology in Toxocara canis infection. In Parasitic Nematodes - Antigens, Membranes and Genes (ed. Kennedy, M. W.), pp. 117-139. Taylor and Francis, London.

Sprent, J. F. A. (1955). On the invasion of the central nervous system by nematodes II. Invasion of the nervous system in Ascariasis. Parasitology 45, 41-58.

Taylor, M. R. H., Keane, C. T., O'Connor, P., Girdwood, R. W. A. and Smith, H. (1987).
Clinical features of covert toxocariasis. Scandinavian Fournal of Infectious Diseases 19, 693-696.

Thomson, D. E., Bundy, D. A. P., Cooper, E. S. and Schantz, P. M. (1986). Epidemiological characteristics of Toxocara canis zoonotic infection of children in a Caribbean community. Bulletin of the World Health Organization 64, 283-290.

Wang, M. Q., Jiang, H. J., Inoue, H., Myozaki, M. and Yamashita, U. (1995). B cell mitogenic activity of Toxocara canis adult worm antigen. Parasite Immunology 17, 609-615.

Wilder, H. C. (1950). Nematode endophdalmitis. Transactions of the American Academy of Opthalmology and Otolaryngology 55, 99-109.

Witting, P. A. (1979). Learning capacity and memory of normal and Toxoplasma-infected laboratory rats and mice. Zeitschrift für Parasitenkunde 61, 29-51.

Worley, G., Green, J. A., Frothingham, T. E., Sturner, R. A., Walls, K. W., Pakalnis, V. A. and Ellis, G. S. Jr. (1984). Toxocara canis infection: clinical and epidemiological associations with seropositivity in kindergarten children. Fournal of Infectious Diseases 149, 591-597. 